\title{
A Phylogenetic Classification of the Video-Game Industry's Business Model Ecosystem
}

\author{
Nikolaos Goumagias ${ }^{1}$, Ignazio Cabras ${ }^{1}$, Kiran Jude Fernandes ${ }^{2}$, Feng Li $^{3}$, \\ Alberto Nucciarelli ${ }^{3}$, Peter Cowling ${ }^{4}$, Sam Devlin ${ }^{4}$, and Daniel Kudenko ${ }^{4}$ \\ ${ }^{1}$ Northumbria University, Newcastle Business School, City Campus East, \\ Newcastle upon Tyne, NE1 8ST, UK \\ ${ }^{2}$ Durham University, Durham University Business School, Mill Hill Lane, Durham, \\ DH1 3LB, UK \\ ${ }^{3}$ University of York, York Centre of Complex System Analysis (YCCSA), \\ Ron Cooke Hub, Heslington YO10 5GE, UK \\ ${ }^{4}$ City University London, Cass Business School, 106 Bunhill Road, London, EC1Y 8TZ, UK
}

\begin{abstract}
Since 1990, Business Models emerged as a new unit of interest among both academics and practitioners. An emerging theme in the growing academic literature is focused on developing a system that employs business models as a focal point of enterprise classification. In this paper we attempt a historical analysis of the video game industry business model evolution and examine the process through the prism of two-sided market economics. Based on the biological school of phylogenetic classification, we develop a cladogram that captures the evolution process and classifies the industry's business models. The classification system is regarded as a first attempt to provide an exploratory and descriptive research of the video game industry, before attempting an explanatory and predictive analysis, and introduces a system that is not governed by the industry's specific characteristics and can be universally applied, providing a map for researchers and practitioners to test organisational differences and contribute further to the business model knowledge.
\end{abstract}

Keywords: Business Models, Video-game Industry, Cladistics Classification, Evolution.

\section{$1 \quad$ Introduction}

The term "Business Model" continues to attract significant attention on behalf of both academics and practitioners since 1995 . However, contrary to how often the term is used, current literature is far from converging in providing a unanimously accepted definition of what a business model actually is [1]. The lack of consensus among scholars over what exactly a business model is has not prevented them from employing the notion at the centre of management theory and strategic management, opening new paths of research [2]. In this Section we aim first and foremost, based on the literature that governs business models, to establish the theoretical foundations of business model evolution through the three evolutionary principles, namely selection, variation, and replication. 
Business models are regarded as something more than a simple recipe or blueprint for organizational change. According to [3], the business model is an opportunitycentric concept while strategic management is an environmental-centric one, rendering business model an integral part of the firm's strategic decisions regarding value creation and capturing. Compared to strategic management, it emphasises on cooperation, partnership and value creation. Consequently strategic management and business models are conceptually complementary [4]. Based on the above, the business model is regarded as a source of innovation and competitive advantage, providing support to the argument that places it at the core of strategic management ([5] and [6]). In other words, business models are viewed as a unified approach, on behalf of the enterprise, to meet different sets of success criteria both financial and non-financial ones ([7] and [8]), circumventing the narrow boundaries of enterprises, and in some cases industries, and has attracted much academic interest focusing on industrial and organisational change. Based on the above, it can be safely argued that business models are selected based on survivability maximization terms ([5] and [9]).

We have already discussed that business models can be a source, or facilitate the creation, of sustainable competitive advantage on behalf of the enterprise. Both intrinsic and extrinsic factors force enterprises to change their corresponding business models to realise both short and long-term strategic goals [10]. The mechanisms that govern this change, usually termed as business model innovation, have also been central to the growing literature. In [11], the authors examined the two sources of change, internal and external, and described these mechanisms in terms of their feasibility and effectiveness. Further work regarding the dynamics of business model innovation includes [12], the authors of which developed a theoretical framework that distinguishes between two interdepended processes, namely design and reconfiguration. The success of the process is governed by experimentation or imitation of other successful examples, usually derived from a given industry. Alternatively, the authors of [13] examined the evolution of electric vehicles business models through the prism of path dependencies. Several studies, including [14], provide evidence that the innovation process is strongly correlated with superior enterprise performance. Consequently, business models can be regarded as a focal point of replication ([1]; [4]; [11]; [12]; and [13]) and variation as the result of business model innovation ([1]; [2]; [10]; [14] and [17]).

In this paper we aim to contribute to the literature by employing business models as a conceptual tool and the focal point of enterprise classification. To achieve that, we shift our viewpoint to the biological school of classification, namely cladistics taxonomy, in order to organize an industry's business models into homogenous groups. We employ the dynamic, and relatively young, industry of video games as a typology to apply this new classification approach and examine its effectiveness. The short lifespan of the video-game industry allow us to perform a more detailed and thorough historical analysis of the industry which is essential for the classification process. As we will describe in Section 3, cladistics classification presents a series of scientific advantages and it is a well-developed and philosophically robust taxonomy approach. The output of our analysis, the cladogram, could be regarded as a map of the evolution process of the industry's business models and could be used to identify the factors that affected this process through time. Our results are interpreted via the 
prism of a two-sided market networking providing empirical evidence that aims to explain the evolution of the industry's business models in order to meet the strategic goals imposed by the two-sided morphology of the industry's market [41].

\section{Related Work}

An emerging theme of the literature revolves around business model classification ([15] and [16]) providing an initial step towards industry analysis and profiling [17]. Business model classification is mainly focused on fast growing and technologically driven industries, similar to the video game industry, because they provide a fertile grown for business models' evolutionary dynamics exploration. Most of the classification attempts were directed to biotechnology and pharmaceuticals ([16]; 24] and [15]), telecommunication and information industry ([19]; [20]) and e-business models ([21];[22]). Regarding, the development of a formal classification framework, in [23] the revenue streams are employed as a criterion, while in [24], the authors developed a two-dimensional classification framework based on the strategic perspectives and economic and operational factors of the enterprise. On the other hand, in [6], a first analogy is attempted between the biological objects of classification, namely species, and enterprises. Finally, [25] introduced a multidimensional e-business model classification system, arguing that the two-dimensional ones are far too limiting.

According to [2], most business model classification approaches are driven by the researcher's knowledge and is followed by a case-study based validation ([26] and [27]) or via the contingency theory ([28] and [15]). Consequently, the taxonomy approaches vary significantly among researchers based on their conceptualization and knowledge. In other words, compared to the biological school of classification, these phenetic approaches, which are based on similarities among the objects of classification are highly subjective [9]. One of the first works that aimed to implement cladistics classification in industrial evolution of manufacturing systems was [9] who argued that cladistics taxonomy provides a classification system that is scientifically more appropriate because of its objectivity.

\section{Methodology}

In this paper we employ the classification methodology as described in [9]. To facilitate discussion we provide a brief, yet solid description of cladistics classification. Cladistics taxonomy in biology classifies organisms based on identifying their most recent common ancestor. Similarities (dictated by characters and their corresponding character states) among organisms are examined in order to track the evolutionary process. However, the major difference between phenetic classification and phylogenetic classification is that, in the latter, entities are classified based on their most recent common ancestor and characters are used to identify that ancestor.

Initially the industry has to be selected which formulates a form of classification as well [9]. In our case it is the video-game industry that interests us, albeit the business models that aim to create and capture value through the development, publication and 
distribution of video games no matter the content of the game (entertainment, fun, engagement, education etc.). In this analysis, we employed an elemental definition of what constitutes a business model based on the works of [30], [31] and [32]. Adopting a more general definition would result in analogies that would erode the descriptive power of our classification. Analogies, in the biological school of classification, are created by grouping entities together using characters inherited from two different ancestors.

\subsection{Character Development and Selection}

In order to determine the characters, a historical analysis is performed to track the milestones of the industry (technological advances, monetisation strategies, customer segments etc.) through the evolution process and identify the appropriate business model characteristics. This process is called Character Search and Selection. The historical analysis was based on published academic papers or reports that describe the operations of various enterprises through history and how they adapted to various environmental and internal factors. We elaborate further on this matter in Section 4.

The selection of a character is validated through a test of homology [33] and character conflict resolution. The process of character conflict resolution is a dynamic one that requires the construction of several conceptual cladograms followed by direct test of homologies. Character conflicts are the main source of creating analogies. Character conflict resolution takes place continually from the point of character determination, selection and conceptual cladogram creation.

The choice among the various conceptual cladograms is governed by the test of parsimony, which means that the clade with the least possible character changes is chosen, based on the parsimony rule which dictates that evolution follows the shortest path. Based on the outgroup comparison, characters are grouped into derived through evolutionary process (variation) and inherited from the most recent common ancestor (outgroup). This process is called "establishing character polarity". Finally, after solving the character conflicts that may occur, the nomenclature is established. In this paper we aimed to define archetypes based on informative and commonly used terms by both academics and practitioners [42].

\section{Data}

Performing a historical analysis presents a significant challenge in order to avoid subjectivity during the process [29]. In our work, historical data are used for two purposes. Firstly, we aim to identify the video-game industry business model archetypes, and secondly the characters that are used for classification purposes. We based our approach on the Business model Canvas developed in [34] followed by a video-game industry historical analysis ([29]; [35], [36]; [37]; [38]; [39] and [40]). The Canvas was also used to facilitate comparison among the different archetypes and as a reference point. Through the historical analysis, we created a time series of case studies and proceeded with a comparative examination focused on Mining for Species and character search and selection. We constructed several conceptual cladograms, followed by a series of parsimony tests. Character conflicts were resolved via a test of 
homology and the most parsimonious cladogram was chosen. The process of archetypes identification is dynamic, and as more data become available new business model archetypes could be identified. However, as new species become known, they enrich the already existent cladogram along with the newly acquired characters without having to undergo a whole character and species rearrangement. The business model archetypes (or species) we have identified through our analysis are 11: i) Outgroup: Electronics Manufacturing, ii) Arcade Games Manufacturing iii) Console Manufacturing, iv) Console Manufacturing-sales-at-a-loss, v) Publishing, vi) Freemium-game publishing, vii) Independent game-developing, viii) Third-party game-developing, ix) In-house game-developing, x) Second-party game-developing, and xi) Crowd-funded game-developing.

Table 1. List of classification characters and character coding

\begin{tabular}{llll}
\hline Code & Character & Code & Character \\
\hline 1 & Platform manufacturing & 19 & Outsourcing publishing \\
2 & Console manufacturing & 20 & Price discrimination \\
3 & Selling-at-a-loss revenue stream & 21 & In-game advertisement \\
4 & Own distribution channels & 22 & Digital distribution \\
5 & Third-party distribution channels & 23 & Outsourcing digital distribution channels \\
6 & Own development studios & 24 & Multidisciplinary development team \\
7 & Outsourcing game development & 25 & Exclusive publishing agreements \\
8 & Localisation services & 26 & Development Independence \\
9 & Video games development & 27 & Revenue stream via royalties \\
10 & Layout design and printing & 28 & More than one publishing contracts \\
11 & Intellectual Property (IP) acquisition & 29 & Small, close-knitted teams \\
12 & IP creation & 30 & Use of middleware \\
13 & Universal development support & 31 & Exit strategy \\
14 & Production risk minimisation strategy & 32 & Cost minimisation strategy \\
15 & High marketing costs & 33 & Engine released as open-source \\
16 & Hit driven strategy & 34 & Crowd-funding \\
17 & Royalty payments & 35 & Self-funding \\
18 & Hardcopy sales & 36 & No platform-manufacturing \\
& & 37 & Owned by publisher \\
\hline
\end{tabular}

The character that were chosen for the classification purposes, based on [34], for systematic reasons are shown in Table 1. For space considerations we will not include a table that contains the character states for each business model archetype of the video-game industry. However, the character evolution (and polarity) can be seen in Figure 1 in the next Section.

\section{$5 \quad$ Results and Discussion}

In this Section we include, and discuss, the factual cladogram that tracks the evolutionary process of the video-game industry's business model archetypes shown in Figure 1. 


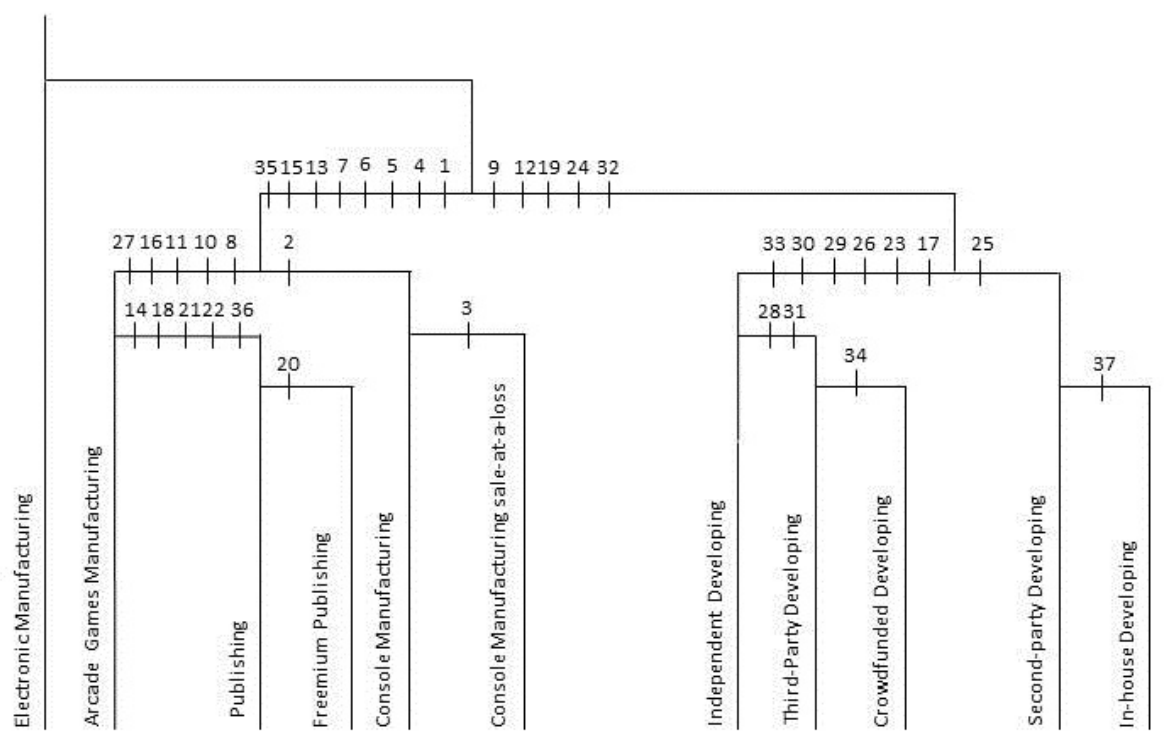

Fig. 1. The Video-games Industry Cladogram: Business model archetypes are grouped together based on their most recent ancestor. Numbers represent the characters that have been inherited or developed through the evolutionary process.

Figure 1 shows the evolution of the video-game industry's business model ecosystem based on their most recent common ancestor. The figure also depicts the evolution of characters through time. Business models are grouped together into two broad categories or families: 1) the Platform Manufacturing and Publishing, and 2) Video-game Developing. We examine the relations among these archetypes and focus our analysis through the prism of two-sided market economics, as part of the networking literature that focuses on the intermediaries of the market [41].

Arcade Games Manufacturing: This business model is focused on manufacturing platforms dedicated to a single game. The enterprises characterized by this business model were combining characteristics of both publishing and manufacturing in an allin-one approach. The key partners were entertainment hubs and public houses which was the main target group of coin-operated machines similar to pinballs. Due to the increased manufacturing costs and the technological limitation vertical disintegration was impossible during the early days of the industry [42]. The vertical disintegration of this family of business models placed the foundations of the video-game market transformation into a two-sided one.

Console manufacturing: with the advent of new technological advances that allowed lower manufacturing costs new platforms, no longer dedicated to a single game, were produced. Console manufacturing business model is focused on maximizing the console sales which are supported by games developed specifically for a given platform preventing cross-platform compatibility. This interdependence between publishing hit-driven titles and player-base maximization was responsible for another business model (sale-at-a-loss), also known as razor-blade, which effectively 
entails that console manufacturing business model focuses on market infiltration maximization instead of profits [43];[44]. To achieve that, the business model needs to establish networks [42] with another business model, namely publishing, operating in a form of two-sided market [41]. It is safe to argue at this point that multi-sided markets determined the emergence of a symbiotic relationship between more than one business models [18]. This business model archetype acts as the intermediary between publishing/developing business models on one hand and customers on the other.

Publishing: the publishing business model is focused on revenue and profit maximization through video-game sales (physically or digitally) following a riskaverse strategy [42] that skews the publishing decision making heavily towards hitdriven titles. The apomorphic event took place when the business model discarded the manufacturing character and focused instead on monetisation strategies of physical and digital copies of video games [45]. This business model acts as the major revenue source and financially supports the console manufacturing business models in a symbiotic relationship, as discussed earlier, and the major source of funding for the Video-game Developing business models. Consequently, Intellectual Property (IP) acquisition and creation, internally via in-house development, is very important for the sustainability of this business model [42]. A specific aspect of two-sided market, publishers currently operate in, led many publishers to follow a price-discrimination strategy, usually called Freemium Business Model [41].

Video-game Developing: this family of business models focuses on the development of original or licensed titles creating new video games for all platforms. The group consists of Independent developing, Crowdfunded Developing, Third-party developing, Second-party developing and In-house developing business models. Their evolutionary trajectory is heavily affected by the relationship they develop against publishing business models which act as their major partners for financing and revenue streams. The major goal is survivability maximisation through production costs minimisation. To overcome these challenges, developing business models focus on the production process and key resources when it comes to business model innovation. Independent developing operates usually under the radar [38]. They employ digital distribution channels to directly sell the products to consumers, or via online markets (GoG, Steam, etc.). Third-party developing business models are focused on creating original titles or entering a contract with a publisher. The challenges that developing-studios face during project financing lead to the emergence of a new business model, namely Crowdfunded-developing, which aims to attract funding directly from customers. This initiated a series of domino effects on the production and monetization process of the games and is heavily based on the loyalty of the customer base, which is placed at the centre of production process for feedback and word-of-mouth marketing strategy. Economies of scale usually lead Publishing and developing business models to merge or acquire competitors [42]. Second-party developing business models are focused on engaging in dedicated contracts with a single publisher who acts as the financier of the project and the final customer. The studios operating under this business model rarely enjoy production independence and are focused on a hit-driven development strategy. Finally, in-house development studios are effectively owned by publishers in a strategically driven strategy to fuel IP creation but usually they operate in a relatively more autonomous way. 


\section{Concluding Remarks}

This paper presents a new classification approach, namely cladistics classification. Assuming that business model change is governed by the three principles of evolution: 1) selection, 2) variation and 3) replication, we employ cladistics classification to group business models based on their most recent common ancestor. Other kinds of classification are based on a two-dimensional, phenetic approach, which in one hand informative, but on the other hand lacks the objectivity and overall applicability, cladistics classification offers an objective and philosophically robust alternative when it comes to business model classification.

We perform a historical analysis of the video games industry, which is used as a typology to examine the applicability of the cladistics classification when it comes to business models. The result of the classification process, namely the cladogram, is validated through the lenses of two-sided market economics and networking and we provide some initial evidence about the dynamics of the video-games-industry business model evolution.

As part of the creative industries, video-game industry business model analysis and classification could potentially be of value for cross-industry fertilization of new and innovative business models that could benefit music and film industry alike. Price discrimination and servitization, along with the dynamics of the business model networking, could provide valuable lessons, highly applicable to other creative industries or industries that share similar attributes as the video-games one.

Acknowledgments. We acknowledge the financial support from the EPSRC and ESRC Digital Economy Programme: NEMOG - New Economic Models and Opportunities for Digital Games, grant number EP/K039857.

\section{References}

1. Zott, C., Amit, R., Massa, L.: The Business Model: Recent Developments and Future Research. Journal of Management 37, 1019-1042 (2011)

2. Lambert, S.C., Davidson, R.A.: Applications of the Business Model in Studies of Enterprise Success, Innovation and Classification: An Analysis of Empirical Research from 1996 to 2010. European Management Journal 31, 668-681 (2013)

3. George, G., Bock, A.J.: The Business Model in Practice and its Implications for Entrepreneurship Research. Entrepreneurship Theory and Practice 35(1), 83-111 (2011)

4. Zott, C., Amit, R.: The Fit between Product Market Strategy and Business Model: Implications for Firm Performance. Strategic Management Journal 29(1), 1-26 (2007)

5. Christensen, C.M.: The Past and Future of Competitive Advantage. MIT Sloan Management Review 42(2), 105-109 (2001)

6. Baden-Fuller, C., Morgan, M.S.: Business Models as Models. Long Range Planning 43, 156-171 (2010)

7. DeYoung, R.: The Performance of Internet-Based Business Models: Evidence from the Banking Industry. The Journal of Business 78(3), 893-947 (2005) 
8. Kshetri, N.: Barriers to e-commerce and Competitive Business Models in Developing Countries: A Case Study. Electronic Commerce Research and Applications 6(4), 443-452 (2007)

9. McCarthy, I., Ridgeway, K., Leseure, M., Fieller, N.: Organisational Diversity, Evolution and Cladistic Classifications. Omega the International Journal of Management Science 28, 77-95 (2000)

10. de Reuver, M., Bouwman, H., MacInnes, I.: Business Models Dynamics for Start-ups and Innovating e-businesses. International Journal of Electronic Business 7(3), 269-286 (2009b)

11. Giesen, E., Riddleberger, E., Christner, R., Bell, R.: When and How to Innovate your Business Model. Strategy \& Leadership 38(4) (2010)

12. Massa, L., Tucci, C.L.: Oxford Handbook of Innovation Management: Business Model innovation (forthcoming)

13. Bohnsack, R., Pinkste, J., Kolk, A.: Business Models for Sustainable Technologies: Exploring Business Model Evolution in the Case of Electric Vehicles. Research Policy 43, 284-300 (2014)

14. Morris, M., Schindehutte, M., Allen, J.: The Entrepreneur's Business Model: Toward a Unified Perspective. Journal of Business Research 58, 726-735 (2005)

15. Patzelt, H., Knyphausen-Aufsess, D., Nikol, P.: Top Management Teams, Business Models, and Performance of Biotechnology Ventures: An Upper Echelon Perspective. British Journal of Management 19, 205-221 (2008)

16. Konde, V.: Biotechnology Business Models: An Indian Perspective. Journal of Commercial Biotechnology 15(3), 215-226 (2009)

17. Ha, L., Ganahl, R.: Webcasting Business Models of Clicks-and-Bricks and Pure-Play media: A comparative Study of Leading Webcasters in South Korea and the United States. The International Journal of Media Management 6(1-2), 74-87 (2004)

18. Sabatier, V., Mangematin, V., Rouselle, T.: From Recipe to Dinner: Business Model Portfolios in the European Biopharmaceutical Industry. Long Range Planning 43(2-3), 431-447 (2010)

19. Eriksson, C.I., Kalling, T.: Proposing a Business Model Framework for the e-newspaper. In: Proceedings of the 15th European Conference on Information Systems (ECIS 2007), St. Gallen, pp. 7-9 (June 2007)

20. Amberg, M.M., Schröder, M.: E-business Models and Consumer Expectations for Digital Audio Distribution. Journal of Enterprise Information Management 20(3), 291-303 (2007)

21. Weill, P., Vitale, M.R.: Place for Space: Migrating to e-Business Models. Harvard Business School Press, Boston

22. Tapscott, D., Lowy, A., Ticoll, D.: Digital Capital: Harnessing the Power of Business Webs. Thunderbird International Business Review 44(1), 5-23 (2000)

23. Rappa, M.: Business Models on the Web: Managing the Digital Enterprise, http: / /www. Digitalenterprise.org/models/models.html

24. Morris, M., Schindehutte, M., Richardson, J., Allen, J.: Is the Business Model a Useful Strategic concept? Conceptual, Theoretical, and Empirical Insights. Journal of Small Business Strategy 17(1), 27-50 (2006)

25. Torbay, M.D., Osterwalder, A., Pigneur, Y.: eBusiness Model Design, Classification and Measurements. Thunderbird International Business Review 44(1), 5-23 (2001)

26. Kauffman, R.J., Wang, B.: Tuning into the Digital Channel: Evaluating Business Model Characteristics for Internet Firm Survival. Information Technology and Management 9(3), 215-232 (2008) 
27. Leem, C.S., Suh, H.S., Kim, D.S.: A Classification of Mobile Business Models and its Applications. Industrial Management + Data Systems 104(1), 78-87 (2004)

28. Carper, W.B., Snizek, W.E.: The Nature and Types of Organizational Taxonomies: An Overview. Academy of Management Review 5(1), 65-75 (1980)

29. Gallagher, S., Park, H.S.: Innovation and Competition in Standard-based Industries: A Historical Analysis of the U. S. Home Video Game Market. IEEE Transactions on Engineering Management 49(1), 67-82 (2002)

30. Chesbrough, H., Rosenbloom, R.S.: The Role of the Business Model in Capturing Value from Innovation: Evidence from Xerox Corporation's Technology Spin-off Companies. Industrial and Corporate Change 11(3), 529-555 (2002)

31. Chesbrough, H.: Business Model Innovation: It's not Just About Technology Anymore. Strategy \& Leadership 35(6), 12-17 (2007)

32. Teece, D.J.: Business Models, Business Strategy and Innovation. Long Range Planning 43(2), 172-194 (2010)

33. de Queiroz, K., Gauthier, J.: Phylogenetic Taxonomy. Annual Review of Ecology and Systematics 23, 449-480 (1992)

34. Osterwalder, A., Pigneur, Y., Tucci, C.I.: Clarifying Business Models: Origins, Present and Future of the concept. Communications of the Association for Information Science (CAIS) 16, 1-25 (2005)

35. Readman, J., Grantham, A.: Shopping for Buyers of Product Development Expertise: How Video Game Developers stay Ahead. European Management Journal 24(4), 256-269 (2006)

36. Claussen, J., Falck, O., Grosjean, T.: The Stregth and Ties: Evidence from the Electronic Game Industry. International Journal of Industrial Organization 30, 223-230 (2012)

37. Storz, C.: Dynamics in Innovation Systems: Evidence from Japan's Game Software Industry. Research Policy 37, 1480-1491 (2008)

38. Haelfiger, S., Jäger, P., von Krogh, G.: Under the Radar: Industry Entry by User Entrepreneurs. Research Policy 39, 1198-1213 (2010)

39. De Vaan, M., Boschma, R., Frenken, K.: Clustering and Firm Performance in ProjectBased Industries: The Case of the Global Video Game Industry, 1972-2007. Journal of Economic Geography, 1-27 (2012)

40. Cadin, L., Guérin, F.: What Can We Learn from the Video Games Industry. European Management Journal 24(4), 248-255 (2006)

41. Rysman, M.: The Economics of Two-Sided Markets. American Economic Association 23(3), 125-143 (2009)

42. Johns, J.: Video Games Production Networks: Value Capture, Power Relations and Embeddedness. Journal of Economic Geography 6, 151-180 (2006)

43. Hagiu, A., Lee, R.S.: Exclusivity and Control. Journal of Economics \& Management Strategy 20(3), 679-708 (2011)

44. Evans, D.S., Hagiu, A., Schmalensee, R.: Invisible Engines. MIT Press (2006)

45. Haddon, L.: The Development of Interactive Games. In: Mackay, H., O’Sullivan, T. (eds.) The Media Reader: Continuity and Transformation. Sage, London (1999) 